\title{
Comparison of haemodynamic responses to dopamine and salbutamol in severe cardiogenic shock complicating acute myocardial infarction
}

\author{
A D TIMMIS, M B FOWLER, D A CHAMBERLAIN
}

\begin{abstract}
Twelve patients with severe persistent cardiogenic shock complicating acute myocardial infarction underwent single crossover treatment with intravenous dopamine and salbutamol to determine the more beneficial therapy. Salbutamol (10 to $40 \mu \mathrm{g} / \mathrm{min}$ ) reduced systemic vascular resistance and progressively increased both cardiac index and stroke index. Heart rate increased from 95 to 104 beats/min. Changes in mean arterial pressure and pulmonary artery end-diastolic pressure were small and insignificant. Dopamine infusion at rates of 200 and $400 \mu \mathrm{g} / \mathrm{min}$ also increased cardiac index and stroke index. Systemic vascular resistance fell slightly but mean arterial pressure rose from 57 to $65 \mathrm{~mm} \mathrm{Hg}$. Heart rate increased from 95 to 105 beats/min. Changes in pulmonary artery end-diastolic pressure were again small and insignificant. Dopamine infusion at 800 $\mu \mathrm{g} / \mathrm{min}$ caused an appreciable increase in systemic vascular resistance; a further increment in mean arterial pressure was observed, though cardiac index fell slightly. Heart rate and pulmonary artery end-diastolic pressure rose steeply.

Salbutamol, a vasodilator, increased cardiac output in patients with cardiogenic shock complicating acute myocardial infarction but did not influence blood pressure. If correction of hypotension is essential dopamine in low doses may be the preferred agent. Doses of $800 \mu \mathrm{g} / \mathrm{min}$, which is within the therapeutic range, worsen other manifestations of left ventricular dysfunction.
\end{abstract}

Department of Cardiology, Royal Sussex County Hospital, Brighton BN2 5BE

A D TIMMIS, MB, MRCP, cardiac registrar (present address: Massachusetts General Hospital, Boston, Mass 02114)

M B FOWLER, MB, MRCP, research registrar (present address: King's College Hospital, London SE5)

D A CHAMBERLAIN, MD, FRCP, consultant cardiologist

\section{Introduction}

Dopamine, a precursor in the endogenous synthesis of noradrenaline is widely used in the treatment of cardiogenic shock complicating acute myocardial infarction ${ }^{1-5}$; blood pressure and cardiac output may both be increased by its agonist activity at $\alpha$ - and $\beta$-adrenoceptors. Recent reports have shown that salbutamol, a relatively specific $\beta_{2}$-adrenoceptor agonist with vasodilator properties, also has beneficial haemodynamic effects in this condition. ${ }^{6}$ ?

Cardiogenic shock carries a mortality close to $100 \%$ when initially refractory or unusually severe. The prompt administration of a drug providing the most suitable haemodynamic support may make a small impact on prognosis and on the quality of life of those who do survive. Unfortunately, few drug comparisons have been made in this condition. Moreover, recommendations for treatment are often based on effects elicited in patients who do not have myocardial damage of an extent that critically limits haemodynamic response. In attempting to provide the most effective treatment for patients with severe cardiogenic shock after myocardial infarction, we compared haemodynamic responses to salbutamol and dopamine since this information has not been available as a guide to management.

\section{Patients and methods}

The haemodynamic effects of dopamine and salbutamol were compared in patients with critical cardiogenic shock who had not responded adequately, or who seemed unlikely to respond, to our conventional treatment, including vasodilators. We used a single crossover design, with the intention of alternating the order in which the drugs were given.

Difficulties arose with the order of drug administration because the patients studied did not constitute a consecutive series of those admitted with shock. Thus several patients were treated electively with salbutamol and one electively with dopamine. Another, whose condition improved considerably with salbutamol, was withdrawn from the study, since a change in treatment at that stage was not considered ethical. Four patients who were considered for the trial died before comparative observations had been made. 
Of the patients remaining in the study, seven received dopamine before salbutamol and five received salbutamol first. Their ages ranged from 49 to 78 years (mean 67). All had electrocardiographic evidence of acute myocardial infarction (eight anterior and four inferior). One patient was in atrial fibrillation, another was paced at a rate of 100 beats $/ \mathrm{min}$, and the remainder were in sinus rhythm. The patients had severe cardiogenic shock with cold clammy skin, systolic blood pressure below $90 \mathrm{~mm} \mathrm{Hg}$, and a urine output of less than $20 \mathrm{ml} /$ hour which had not increased with intravenous diuretics. No other inotropic or vasodilator drugs were given during the study, though all the patients were well sedated with opiates and eight had been given digitalis.

Observations were made in the coronary care unit within 36 hours of admission. Radial artery and right heart pressures and cardiac output were measured as previously described. ${ }^{6}$

Dopamine and salbutamol were each diluted in 5\% dextrose and administered by an infusion pump (Watson Marlow Ltd) into a central vein. Dopamine was infused at 200 then 400 and finally $800 \mu \mathrm{g} / \mathrm{min}$. Salbutamol was infused at 10 then 20 and finally 40 $\mu \mathrm{g} / \mathrm{min}$. Infusion rates were increased every 20 minutes and haemodynamic measurements were made before each dose increment. After the maximal dose increment of each drug the infusions were discontinued and further haemodynamic measurements made 30 minutes later. At the end of the study the patients were treated with the agent which had produced the more favourable haemodynamic response.

The variation in cardiac output within any set of readings for the 12 patients did not exceed $0.3 \mathrm{l} / \mathrm{min}$. Peripheral resistance was calculated in arbitrary units as mean arterial pressure in $\mathrm{mm} \mathrm{Hg}$ divided by cardiac output in $1 / \mathrm{min}$. Stroke work index $\left(\mathrm{g} \mathrm{m} / \mathrm{m}^{2}\right)$ was calculated as the difference between mean arterial pressure and pulmonary artery end-diastolic pressure in $\mathrm{mm} \mathrm{Hg}$ multiplied by stroke index $\left(\mathrm{ml} /\right.$ beat $\left./ \mathrm{m}^{2}\right)$ multiplied by 0.0144 .

The reasons for the infusions and observations were explained to the patients but no written consent was obtained. We believe that this was in the best interests of the patients since all were receiving conventional treatment and our main interest was to select the most effective infusion on an individual basis. A more formal approach may have unnecessarily increased both anxiety and risk. The protocol was approved by the hospital ethical committee.

Student's $t$ test for paired data was used for statistical comparisons.

\section{Results}

The haemodynamic effects of dopamine and salbutamol infusions are summarised in the table, and dose response curves are shown in in the figure. Salbutamol caused a progressive dose-related increase in cardiac index and stroke index. Heart rate increased by only

Haemodynamic effects of salbutamol and dopamine in cardiogenic shock in 12 patients. Values are means $\pm S E M$

\begin{tabular}{|c|c|c|c|c|c|}
\hline & & Control & $\begin{array}{c}\text { 1st } \\
\text { increment }\end{array}$ & $\begin{array}{l}\text { 2nd } \\
\text { increment }\end{array}$ & $\begin{array}{l}\text { 3rd } \\
\text { increment }\end{array}$ \\
\hline \multirow{4}{*}{$\begin{array}{l}\text { Cardiac index }\left(1 / \mathrm{min} / \mathrm{m}^{2}\right) \\
\text { Heart rate (beats/min) } \ldots \\
\text { Mean systemic arterial } \\
\text { pressure (mm Hg) } \\
\text { Right atrial pressure (mm }{ }^{2} \text {. } \\
\text { Pulmonary artery end-diastolic } \\
\text { pressure (mm Hg) } \\
\text { Systemic vascular resistance }\end{array}$} & & Salbutamol & \multirow{2}{*}{$\begin{array}{c}10 \mu \mathrm{g} / \mathrm{min} \\
1.8 \pm 0 \cdot 2 \ddagger \\
98 \pm 6 \dagger\end{array}$} & \multirow{2}{*}{$\begin{array}{l}20 \mu \mathrm{g} / \mathrm{min} \\
2 \cdot 1 \pm 0 \cdot 1 \S \\
103 \pm 6 \ddagger\end{array}$} & \multirow{2}{*}{$\begin{array}{l}40 \mu \mathrm{g} / \mathrm{min} \\
2 \cdot 2 \pm 0 \cdot 28 \\
104 \pm 6 \ddagger\end{array}$} \\
\hline & $\because$ & $\begin{array}{l}1 \cdot 6 \pm 0 \cdot 1 \\
95 \pm 7\end{array}$ & & & \\
\hline & $\because$ & $\begin{aligned} 59 & \pm 4 \\
3 & \pm 1\end{aligned}$ & $\begin{array}{r}60 \pm 3 \\
2 \pm 1\end{array}$ & $\begin{aligned} 61 & \pm 3 \\
2 & \pm 1\end{aligned}$ & $\begin{array}{r}60 \pm 4 \\
2 \pm 1\end{array}$ \\
\hline & $\cdots$ & $18 \pm 1$ & $18 \pm 1$ & $17 \pm 1$ & $18 \pm 1$ \\
\hline Stroke volume index $\quad \cdots$ & $\cdots$ & $21 \pm 3$ & $19 \pm 2 \ddagger$ & $16 \pm 2 \ddagger$ & $15 \pm 28$ \\
\hline Stroke work index $\left(\mathrm{g} \mathrm{m} / \mathrm{m}^{2}\right)$ & $\because$ & $\begin{array}{l}17 \pm 2 \\
10 \pm 1\end{array}$ & $\begin{array}{l}18 \pm 2 \dagger \\
11 \pm 1^{*}\end{array}$ & $\begin{array}{l}20 \pm 2 \ddagger \\
13 \pm 1 \ddagger\end{array}$ & $\begin{array}{l}21 \pm 28 \\
13 \pm 1 \ddagger\end{array}$ \\
\hline $\begin{array}{l}\text { Cardiac index }\left(1 / \mathrm{min} / \mathrm{m}^{2}\right) \\
\text { Heart rate (beats/min) } \\
\text { Mean systemic arterial }\end{array}$ & $\because$ & $\begin{array}{l}1 \cdot 7 \pm 0 \cdot 1 \\
95 \pm 6\end{array}$ & $\begin{array}{c}200 \mu \mathrm{g} / \mathrm{min} \\
1.9 \pm 0 \cdot 1 \dagger \\
98 \pm 5\end{array}$ & $\begin{array}{c}400 \mu \mathrm{g} / \mathrm{min} \\
2 \cdot 1 \pm 0 \cdot 1 \ddagger \\
105 \pm 6 \ddagger\end{array}$ & $\begin{array}{l}800 \mu \mathrm{g} / \mathrm{min} \\
2 \cdot 0 \pm 0 \cdot 1 \ddagger \\
119 \pm 5 \S\end{array}$ \\
\hline $\begin{array}{l}\text { pressure (mm Hg) } \\
\text { Right atrial pressure (mm Hg) } \\
\text { Pugresto }\end{array}$ & $\because$ & $\begin{aligned} 57 & \pm 3 \\
3 & \pm 1\end{aligned}$ & $\begin{array}{r}60 \pm 3 \\
3 \pm 1\end{array}$ & $\begin{array}{r}65 \pm 4 \\
3 \pm 1\end{array}$ & $\begin{array}{c}73 \pm 5 \dagger \\
5 \pm 1\end{array}$ \\
\hline $\begin{array}{l}\text { Pulmonary ares } \\
\text { pressure (mm Hg) } \\
\text { Systemic vascular resistance }\end{array}$ & $\cdots$ & $18 \pm 1$ & $17 \pm 1$ & $19 \pm 2$ & $25 \pm 2 \dagger$ \\
\hline Stroke volume index & $\cdots$ & $19 \pm 2$ & $17 \pm 2^{*}$ & $18 \pm 1$ & $20 \pm 2$ \\
\hline $\begin{array}{l}\left(\mathrm{ml} / \text { beat } / \mathrm{m}^{2}\right) \\
\text { Stroke work index }\left(\dot{\mathrm{g}} \mathrm{m} / \mathrm{m}^{2}\right)\end{array}$ & $\because$ & $\begin{array}{l}18 \pm 1 \\
10 \pm 1\end{array}$ & $\begin{array}{l}19 \pm 1 \dagger \\
12 \pm 1 \ddagger\end{array}$ & $\begin{array}{l}20 \pm 1 \dagger \\
14 \pm 2 \dagger\end{array}$ & $\begin{array}{l}17 \pm 1 \\
12 \pm 1\end{array}$ \\
\hline
\end{tabular}

Reference point for pressures was sternal angle (add $5 \mathrm{~mm} \mathrm{Hg}$ to equate with midchest readings). $<0.05 ; \dagger<0.02 ; \ddagger<0.01 ; 8<0.001$.
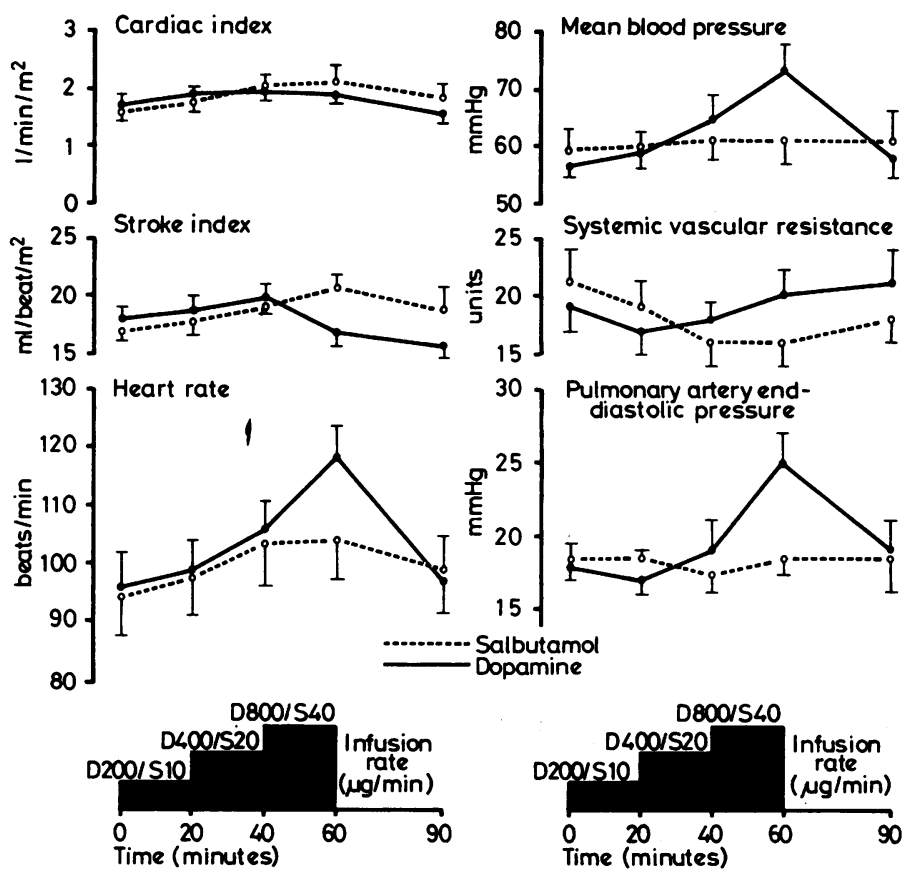

Effect on cardiac index, stroke index, heart rate, mean blood pressure, systemic vascular resistance, and pulmonary artery end-diastolic pressure of dopamine (D) and salbutamol (S) infusions in 12 patients. Observations were made before, during, and after drug intervention. Values are means \pm SEM. Reference point for pressures was sternal angle (add $5 \mathrm{~mm} \mathrm{Hg}$ to equate with mid-chest values).

9 beats/min at the maximum dose increment. Blood pressure was not appreciably altered despite a progressive reduction in systemic vascular resistance. Changes in pulmonary artery end-diastolic pressure were small and not statistically significant.

Dopamine infusion at the first and second dose increments (200 and $400 \mu \mathrm{g} / \mathrm{min}$ ) also caused dose-related increments in cardiac index and stroke index. Heart rate increased by only 10 beats $/ \mathrm{min}$. Mean blood pressure increased by $8 \mathrm{~mm} \mathrm{Hg}$ despite a small reduction in systemic vascular resistance. Changes in pulmonary artery enddiastolic pressure were small and not statistically significant.

With the infusion of dopamine at $800 \mu \mathrm{g} / \mathrm{min}$ a small fall in cardiac index was observed. Moreover, the heart rate increased considerably, resulting in a sharp decline in stroke index. Blood pressure continued to rise as a result of increased systemic vascular resistance. Pulmonary artery end-diastolic pressure rose steeply.

The mean value for stroke work index before treatment was only $10 \mathrm{~g} \mathrm{~m} / \mathrm{m}^{2}$ (range $5-15 \mathrm{~g} \mathrm{~m} / \mathrm{m}^{2}$ ). Despite useful increments in this variable with both dopamine and salbutamol the median survival was only five days (range 1 to 14 days), and no patient survived to leave hospital.

\section{Discussion}

Cardiogenic shock in acute myocardial infarction occurs when at least $45 \%$ of the left ventricle has been damaged. ${ }^{8}$ The most important haemodynamic consequence is a critical reduction in cardiac output with systemic hypotension and impaired perfusion of vital organs. Left ventricular filling pressure is also often considerably raised, resulting in pulmonary oedema. Treatment is aimed at correcting these haemodynamic indices without incurring an unacceptable metabolic cost to the ischaemic myocardium.

Dopamine is an adrenergic agonist. Stimulation of cardiac $\beta$-receptors ${ }^{2}$ and arteriolar $\alpha$-receptors ${ }^{10}$ accounts, respectively, for its inotropic and pressor activity. It also causes direct dilatation of the renal and mesenteric vascular beds. ${ }^{1011}$ Salbutamol too is an adrenergic agonist but has $\beta_{2}$-specificity ${ }^{12}$ and thereby induces peripheral arteriolar dilatation with little direct cardiotropic activity. This allows cardiac output to increase by reducing left ventricular afterload. 
Our results confirm that in patients with cardiogenic shock salbutamol reduces systemic vascular resistance and improves cardiac output. ${ }^{6}$ The increase in cardiac output is sufficient to offset any tendency for blood pressure to fall in response to arteriolar dilatation.

The more complex actions of dopamine are reflected in our data, which show important differences in the type of response depending on the infusion rate. At all doses dopamine acted on the myocardium to increase heart rate and, by inference, contractility. The peripheral effects of dopamine, however, were also important. The selective arteriolar dilatation was clearly dominant at low doses and was responsible for the small fall in vascular resistance at $200 \mu \mathrm{g} / \mathrm{min}$. Thereafter its more gradual $\alpha$-agonist (noradrenaline-like) action became more important, as reflected by the progressive rise in vascular resistance and blood pressure. Despite continuing inotropic drive, a damaged myocardium cannot respond adequately to the increased pressure load. Thus at the highest dose increment in our patients the indirect left atrial pressure rose steeply, tachycardia increased strikingly, and the rise in cardiac output was attenuated.

We have previously postulated ${ }^{6}$ that salbutamol, with its dominantly peripheral mode of action, increases cardiac output at little cost to the heart in terms of oxygen consumption. The effect of dopamine on heart rate and blood pressure with infusion at $800 \mu \mathrm{g} / \mathrm{min}$ indicates that this drug can increase myocardial oxygen requirements considerably. A recent study ${ }^{5}$ investigating the effects of dopamine on myocardial metabolism confirms that the drug is potentially harmful to the ischaemic myocardium.

These adverse haemodynamic and metabolic effects of dopamine are very similar to those observed by Leier et al ${ }^{13}$ in patients with congestive cardiomyopathy. To some extent the ill effects may be mitigated by simultaneously infusing vasodilators such as nitroprusside, ${ }^{14}{ }^{15}$ which reduce myocardial oxygen demand and further increase cardiac output by their action on left ventricular afterload. Salbutamol and nitroprusside also have useful additive effects in severe left ventricular failure $^{16}$ and some of our patients were continued on such combination regimens when optimum doses of dopamine and salbutamol had been selected.

We did not formally measure the effects of these agents on urine output since routine bladder catheterisation in cardiogenic shock was not then our practice. Previous work has shown that dopamine selectively increases renal blood flow ${ }^{1317}$ and will often induce a diuresis in patients with oliguric heart failure. ${ }^{134}$ Salbutamol reliably increases cardiac output in such patients but we do not know whether renal perfusion is improved; dilatation of cutaneous and muscular vascular beds might divert flow away from vital organs. We have been impressed, however, by the urinary response of our patients to salbutamol, implying that this drug-like dopamine-improves renal perfusion.

This group of patients constituted a selected series with severe cardiogenic shock as reflected by a mean stroke work index before treatment of only $10 \mathrm{~g} \mathrm{~m} / \mathrm{m}^{2}$. Mortality approaches $100 \%$ in such patients, ${ }^{18}$ and the uniformly unfavourable outcome in our patients was therefore disappointing but not surprising.

The data we obtained may not reflect responses in those with less severe myocardial damage. In particular, patients with smaller infarcts would be capable of greater increments in cardiac output and may have tolerated more readily the rise in blood pressure caused by the peripheral actions of dopamine. If drugs are to be used successfully for cardiogenic shock we believe that patients should be treated promptly before shock becomes irreversible. Drug selection should depend on the pattern of the haemodynamic derangement in individual patients.

Our findings show that both dopamine and salbutamol increase cardiac output in patients with cardiogenic shock complicating acute myocardial infarction. Neither drug reduces left atrial pressure unless venodilators are used concurrently. ${ }^{14-16}$ If correction of low output is the primary aim salbutamol may be preferred to dopamine since it is likely to be more sparing in its demands on myocardial oxygen consumption. Salbutamol, however, does not influence blood pressure, and when correction of hypotension is of overriding importance dopamine is more useful. Caution is necessary, however, since larger doses of dopamine $(800 \mu \mathrm{g} / \mathrm{min})$ worsen other manifestations of left ventricular dysfunction.

We thank Glaxo Group Research Limited and American Critical Care (UK) Limited (Arnar Stone) for financial support.

\section{References}

1 MacCannell KL, McNay JL, Meyer MB, Goldberg LI. Dopamine in the treatment of hypotension and shock. $N$ Engl f Med 1966;275:1389-98.

2 Talley RC, Goldberg LI, Johnson CE, McNay JL. A hemodynamic comparison of dopamine and isoprotorenol in patients in shock. Circulation $1969 ; 39: 361-78$.

${ }^{3}$ Loeb HS, Winslow EBJ, Rahimtoola SH, Rosen KM, Gunnar RM. Acute hemodynamic effects of dopamine in patients with shock. Circulation $1971 ; 44: 163-73$

4 Holzer J, Karliner JS, O'Rourke RA, Pitt W, Ross J, Jr. Effectiveness of dopamine in patients with cardiogenic shock. Am F Cardiol 1973; 32:79-84

5 Mueller HS, Evans R, Ayres SM. Effect of dopamine on hemodynamics and myocardial metabolism in shock following acute myocardial infarction in man. Circulation 1978;57:361-5.

6 Timmis AD, Strak SK, Chamberlain DA. Haemodynamic effects of salbutamol in patients with acute myocardial infarction and severe left ventricular dysfunction. $\mathrm{Br}$ Med $\mathcal{F} 1979 ; \mathrm{ii}: 1101-3$.

7 Dawson JR, Poole-Wilson PA, Sutton GC. Salbutamol in cardiogenic shock complicating acute myocardial infarction. $\mathrm{Br}$ Heart $\mathcal{F} 1980$; $43: 523-6$.

${ }^{8}$ Caulfield JB, Dunkman WB, Leinbach RC. Cardiogenic shock. Myocardial morphology with and without artificial left ventricular counter-pulsation. Archives of Pathology 1972 ;93:532-6.

- Holmes JC, Fowler NO. Direct cardiac effects of dopamine. Circ Res $1962 ; 10: 68-72$.

10 Goldberg LI, Ley BK. Attenuation of dopamine-induced renal vasodilatation in the dog by phenothiazines. Eur $\mathcal{F}$ Pharmacol 1971;15:36-40.

${ }^{11}$ Higgins CB, Millard RW, Braunwald E, Vatner SF. Effects and mechanisms of action of dopamine on regional hemodynamics in the conscious dog. Am ₹ Physiol 1973;225:432-7.

12 Ablad B, Carlsson B, Carlsson E, Dahlof C, Ek L, Hultberg E. Cardiac effects of beta-adrenergic receptor antagonists. Adv Cardiol 1974;12: 290-302.

13 Leier CV, Heban PT, Huss P, Bush CA, Lewis RP. Comparative systemic and regional hemodynamic effects of dopamine and dobutamine in patients with cardiomyopathic heart failure. Circulation 1978;58:466-75.

14 Miller RR, Awan NA, Joye JA, et al. Combined dopamine and nitroprusside therapy in congestive heart failure. Circulation $1977 ; 55: 881-4$

15 Stemple DR, Kleiman JH, Harrison DC. Combined nitroprussidedopamine therapy in severe chronic congestive heart failure. Am $\mathfrak{f}$ Cardiol 1978;42:267-75.

16 Fowler MB, Timmis AD, Chamberlain DA. Synergistic effects of combined salbutamol-nitroprusside regimen in acute myocardial infarction and severe left ventricular failure. $\mathrm{Br} \mathrm{Med} \mathcal{F} 1980 ; 280: 435-7$

17 Hollenberg NK, Adams DF, Mendell P, Abrams HL, Merrill JP. Renal vascular responses to dopamine; haemodynamic and angiographic observations in normal man. Clin Sci Mol Med 1973;45:733-42.

18 Chatterjee K, Swann HJC, Kaushik VS, Jobin G, Magnusson P, Forrester JS. Effects of vasodilator therapy for severe pump failure in acute myocardial infarction on short-term and late prognosis. Circulation $1976 ; 53: 797-802$.

(Accepted 23 October 1980)

ONE HUNDRED YEARS AGO Last week the London Temperance Hospital was formally opened by the Lord Mayor. According to the statement read, the hospital was first opened at 112, Gower Street, on the 3rd of October, 1873, and had since relieved 954 inpatients and 8,006 out-patients. It was established to give a scientific trial to the non-alcoholic treatment of disease; and although provision was made for the use of alcohol should the medical staff deem it necessary in any special case, yet in point of fact, this provision had been acted upon but once, and that without benefit to the patient herself. Many severe cases, both medical and surgical, had been treated on the non-alcoholic system with marked success, and the Board had thus been encouraged to provide the larger field of hospital practice inaugurated that day. (British Medical fournal, 1881.) 